\title{
DEFINIÇÃO DO LIMITE ANTEROLATERAL DO LOBO OCCIPITAL EM PEÇAS ANATÔMICAS E EXAMES DE IMAGEM
}

\author{
Sebastião Gusmão, Cassius Reis, Uedson Tazinaffo, Celso Mendonça, Roberto Leal Silveira
}

\begin{abstract}
RESUMO - Com o objetivo de definir o limite anterolateral do lobo occipital foram estudados sete segmentos cefálicos de cadáveres humanos, 103 exames de tomografia computadorizada e 104 exames de ressonância magnética do encéfalo considerados normais. Foram encontradas uma prega da dura-máter sobre o seio transverso (plica tentorial pré-occipital) e uma protuberância óssea relacionadas diretamente com a incisura pré-occipital. Foi calculada, também, a distância média entre o sulco parieto-occipital e a sutura lambdóide. Nos exames de imagem, especialmente na ressonância magnética, foi possível identificar a incisura pré-occipital e/ou a protuberância na parede craniana relacionada a ela, bem como o sulco parieto-occipital e a sutura lambdóide, referências que permitem a definição do limite anterolateral do lobo occipital.
\end{abstract}

PALAVRAS-CHAVE: lobo occipital, neuroanatomia, tomografia computadorizada, ressonância magnética.

\begin{abstract}
Definition of the anterolateral occipital lobe limit in anatomical specimens and with neuroimaging
ABSTRACT - The anterolateral limit of the occipital lobe was studied in anatomical specimens and with neuroimaging. Seven human cadaver heads, 103 normal CT-scan and 104 MRJ of the brain were studied. There was a fold of the dura mater on the transverse sinus (preoccipital tentorial plica) and a bony protuberance related directly to the preoccipital notch. It was also determined the mean distance between the parietooccipital sulcus and the lambdoid suture. In the imaging studies, especially magnetic resonance, it was possible to identify the preoccipital notch and/or a protuberance in the cranial vault related to this notch, besides the parieto-occipital sulcus and lambdoid suture, making possible, therefore, the definition of the anterolateral limit of the occipital lobe.
\end{abstract}

KEY WORDS: occipital lobe, neuroanatomy, CT scan, magnetic resonance imaging.

Em procedimentos neurocirúrgicos, é de importância fundamental a precisa localização de determinada lesão em relação aos lobos cerebrais. Esta localização, em relação ao lobo frontal, às porções anteriores dos lobos temporal e parietal, e à porção posterior do lobo occipital (LO), é feita facilmente em exames de imagem, como a tomografia computadorizada (TC) e a ressonância magnética (RM). $O$ mesmo não ocorre com as lesões das porções posteriores dos lobos temporal e parietal e aquelas da porção anterior do LO. Isso decorre da delimitação imprecisa entre estes lobos na face superolateral do hemisfério cerebral. O LO, em sua face superolateral, é separado dos lobos parietal e temporal pela linha imaginária que une a terminação do sulco parietooccipital, no bordo superomedial do hemisfério, à incisura pré-occipital, na borda inferolateral do hemisfério.
O objetivo deste estudo é determinar referências anatômicas para a definição do limite anterolateral do LO em cadáveres humanos e em imagens de TC e RM.

\section{MÉTODO}

Sete segmentos cefálicos de cadáveres humanos, submetidos a fixação em solução de formol e a injeção da rede vascular arterial e venosa com látex colorido, bem como 103 TC, obtidas em aparelho Toshiba X press - GX e 104 imagens por RM, obtidas em aparelho Siemens de 1,5 tesla, consideradas normais, foram utilizados.

Realizou-se craniotomia têmporo-parieto-ocipital bilateral dos cadáveres, preservando-se medialmente a sutura sagital e, no meio da craniotomia, estreita ponte óssea correspondente à sutura lambdóide. Inferiormente, a craniotomia tangenciava a sutura parieto-mastóidea, expondo a borda superior do seio transverso. Seguiu-se a

Laboratório de Microcirurgia da Faculdade de Medicina da Universidade Federal de Minas Gerais (UFMG), Belo Horizonte MG, Brasil.

Recebido 14 Julho 2001, recebido na forma final 25 Setembro 2001. Aceito 5 Outubro 2001.

Dr. Sebastião Gusmão - Rua Padre Rolim 921 / 21 - 30130-090 Belo Horizonte MG - Brasil. 
identificação, ao microscópio cirúrgico, no espaço extradural, do ponto lateral da borda superior da pirâmide petrosa e da protuberância óssea em torno do ponto de encontro entre a sutura lambdóide e a borda superior do sulco do seio transverso. A dura-máter foi aberta e pediculada junto ao seio sagital superior. Após a elevação do lobo temporal, foram identificados o ângulo sinodural e a incisura pré-occipital; foi também observada a relação desta incisura com uma prega sobre a grande circunferência da tenda do cerebelo, na parede superior do seio transverso (plica tentorial pré-occipital).

Foram realizadas as medidas entre os seguintes pontos: da plica tentorial pré-occipital ao ponto de junção entre a sutura lambdóide e a borda superior do sulco do seio transverso (PTPO-SL); da plica tentorial pré-occipital ao ponto lateral da borda superior da pirâmide petrosa (ângulo sinodural) (PTPO-PP); de lambda à terminação do sulco parieto-occipital na borda superomedial do hemisfério cerebral (L-SPO).

As imagens de TC e RM foram escolhidas aleatoriamente dentre os exames considerados normais, realizados no Serviço de Imagem do Hospital Madre Teresa. Em $58,3 \%(60)$, os pacientes eram do sexo feminino e a idade variava de 12 a 96 anos (média de 56 anos). Nas imagens axiais por RM e TC procurou-se definir a incisura pré-occipital e a elevação óssea relacionada à mesma. Nas imagens sagitais de RM mediu-se a distância entre lambda e a terminação do sulco parieto-occipital na borda superomedial do hemisfério cerebral.

\section{RESULTADOS}

Encontrou-se, em todas as peças anatômicas, na grande circunferência da tenda do cerebelo, sobre o seio transverso, uma prega da dura-máter a que se propõe o nome de plica tentorial pré-occipital (Fig 1). Na face interna do crânio a plica tentorial préoccipital correspondia a uma pequena protuberância óssea próxima ao ponto na qual a sutura lambdóide cruza a borda superior do sulco do seio transverso. Essa protuberância óssea e a plica tentorial pré-occipital colada a ela, mostraram estar em relação dire- ta com a incisura pré-occipital em todos os espécimes examinados (Fig 2).

A distância entre a plica tentorial pré-occipital, bem como a correspondente incisura pré-occipital, e o ponto de junção da sutura lambdóide com a borda superior do sulco do seio transverso (ponto logo acima do astério) foi, em média, 2,3 $\mathrm{mm}$ $( \pm 3,36)$. Já aquela entre a plica tentorial pré-occipital e o ponto lateral da borda superior da pirâmide petrosa (ângulo sinodural) foi $18,8 \mathrm{~mm}( \pm 7,92)$. Enquanto aquela entre o lambda e a terminação do sulco parieto-occipital, na borda superomedial do hemisfério cerebral foi $11,5 \mathrm{~mm}( \pm 4,4)$ (Tabela 1$)$.

Em 54,3\% das imagens de TC encontraram-se uma ou ambas as estruturas (incisura pré-occipital ou protuberância óssea correspondente) que podem ser aceitas como referência para a determinação do limite inferior da face superolateral do LO (Tabela 2, Fig 3). A protuberância óssea corresponde, no cadáver, ao local de inserção da plica tentorial pré-occipital na parede craniana. Sua identificação na TC se presta, portanto, como referência anatômica para a localização da incisura pré-occipital.

Em 97,12\% das imagens de RM encontraram-se uma ou ambas as estruturas (incisura pré-occipital ou elevação óssea correspondente) (Fig 3) que podem ser aceitas como referência, para a determinação do limite inferior da face anterolateral do LO (Tabela 3). Em 187 (89,9\%) lados dos 104 exames contrastados de RM, foi identificada uma imagem de vaso junto à incisura pré-occipital, correspondente à veia de Labbé (Fig 3).

O lambda e a extremidade superior do sulco parieto-occipital foram identificados em todos os exames de RM, no corte sagital mediano ou paramediano (5 mm lateral) (Figs 4 e 5). A distância entre ambos foi, em média, de 9,67 mm nas 208 medições (104 exames), com mediana de 9,3 e desvio padrão de 6,10.

Tabela 1. Mediana (Med), média aritmética (Media) e desvio padrão (Desv) em mm das medidas realizadas em peças anatômicas: prega dural à junção da sutura lambdóide com a borda superior do seio transverso (PTPO-SL); prega dural ao ponto lateral da borda superior da pirâmide petrosa (PTPO-PP); lambda à extremidade superior do sulco parieto-occipital (L-SPO).

\begin{tabular}{lccccccccc}
\hline \multirow{2}{*}{ Distância } & \multicolumn{3}{c}{ Lado direito } & \multicolumn{3}{c}{ Lado esquerdo } & \multicolumn{3}{c}{ Ambos lados } \\
& Med & Media & Desv & Med & Media & Desv & Med & Media & Desv \\
\hline PTPO-SL & 0,5 & 3,1 & 4,62 & 1,0 & 1,6 & 2,36 & 1,0 & 2,3 & 3,36 \\
PTPO-PP & 17,0 & 14,8 & 7,43 & 25,0 & 22,8 & 6,83 & 18,5 & 18,8 & 7,92 \\
L-SPO & 10,0 & 10,3 & 5,51 & 13,0 & 12,7 & 3,42 & 11,0 & 11,5 & 4,4 \\
\hline
\end{tabular}






Fig 1. Corte axial do crânio, em vista superior, mostrando, na grande circunferência da tenda do cerebelo (seio transverso, ST), a plica tentorial pré-occipital (PTPO) e a veia de Labbé (VL).

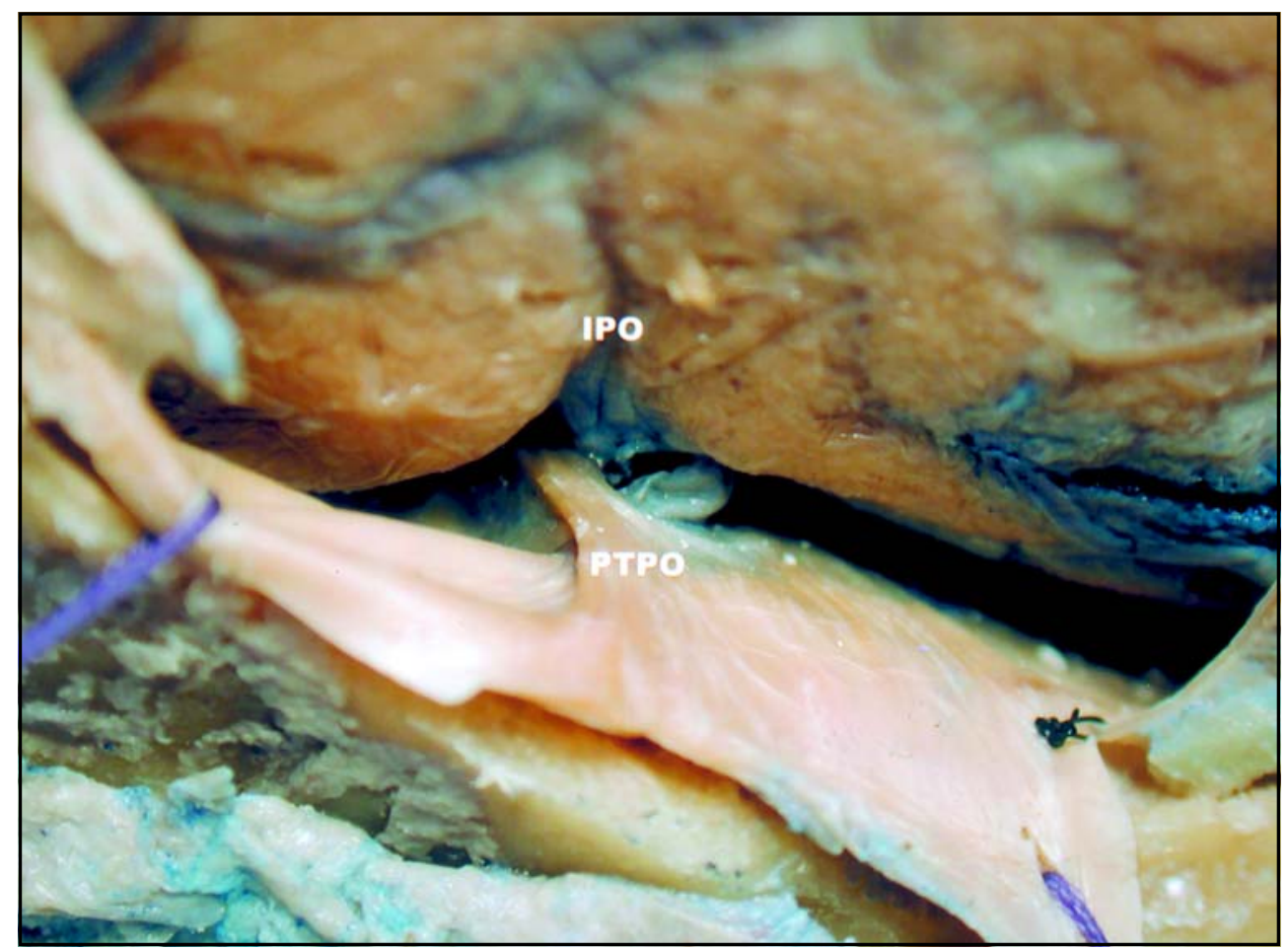

Fig 2. Vista lateral da borda inferolateral do hemisfério cerebral direito, mostrando a incisura pré-occipital (IPO) e da grande circunferência da tenda do cerebelo, mostrando a plica tentorial pré-occipital (PTPO). 


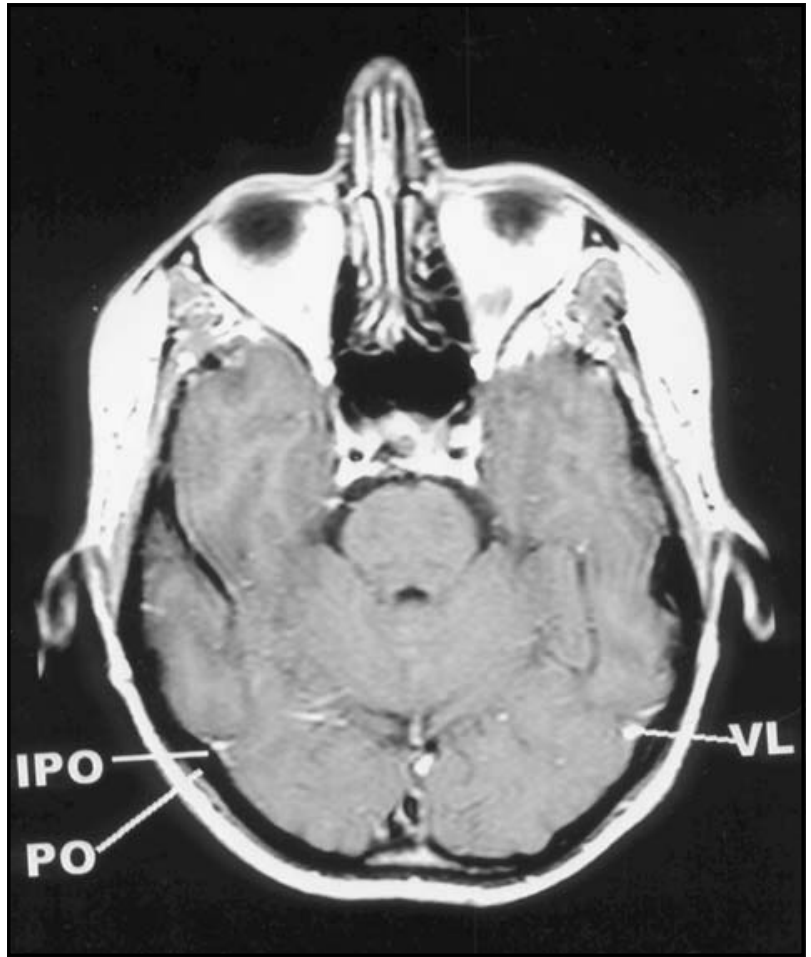

Fig 3. Corte axial de ressonância magnética mostrando a incisura pré-occipital (IPO), a protuberância óssea (PO) a ela associada e a veia de Labbé (VL).

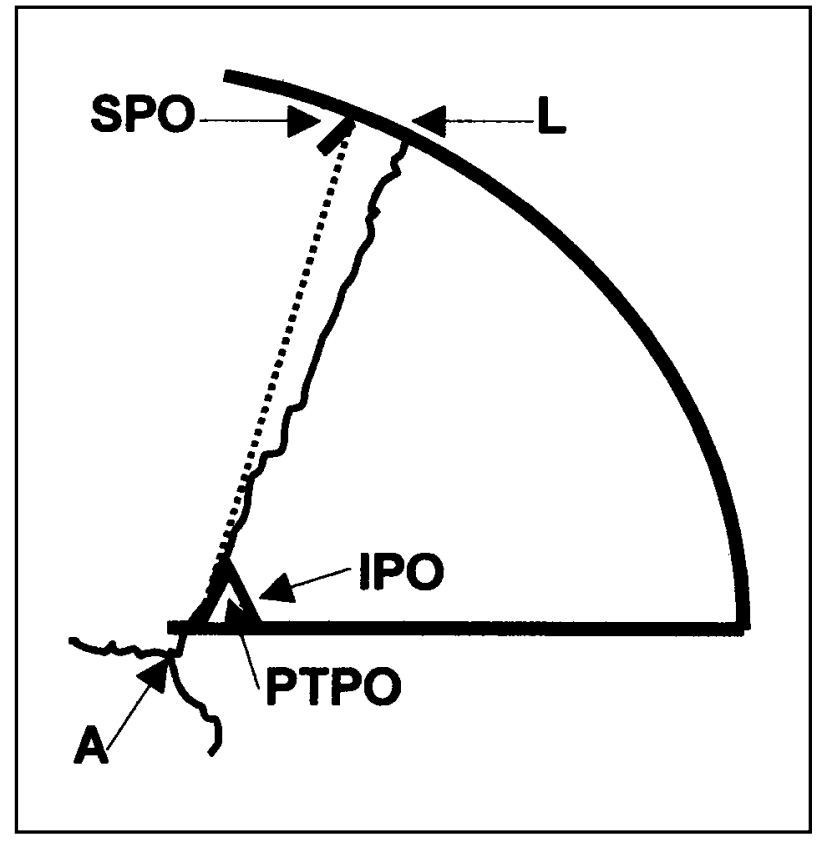

Fig 4. Esquema da face superolateral do lobo occipital esquerdo mostrando as referências ósteo-durais (lambda, sutura lambdóide, astério e plica tentorial pré-occipital) e corticais (incisura préoccipital e sulco parieto-occipital) que permitem traçar o limite anterolateral do lobo occipital (linha sulco parieto-occipital incisura pré-occipital). L: lambda; SL: sutura lambdóide; $A$ : astério; PTPO: plica tentorial pré-occipital; SPO: sulco parietooccipital; IPO: incisura pré-occipital.

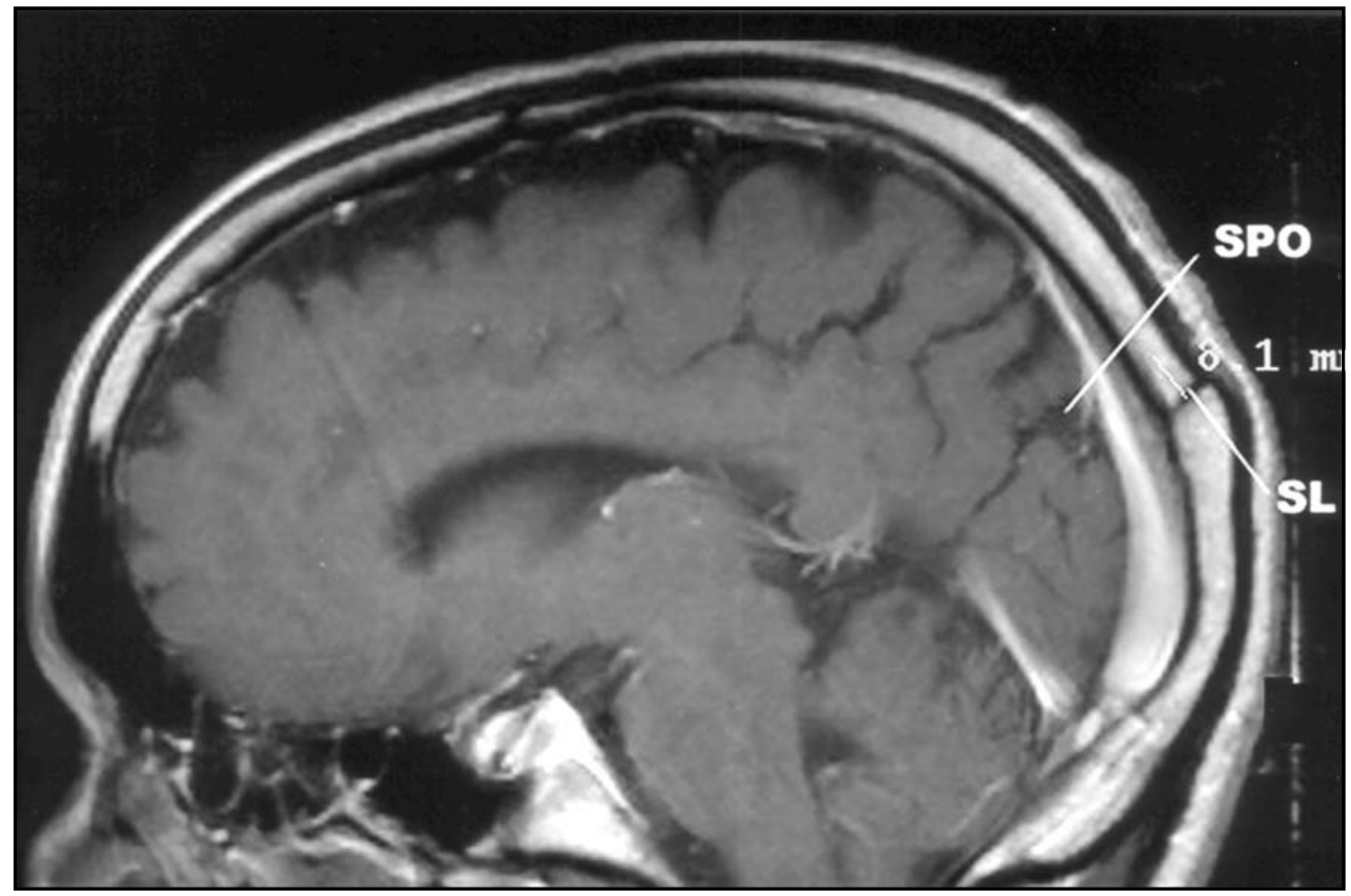

Fig 5. Corte sagital paramediano de ressonância magnética mostrando a sutura lambdóide (SL) e o sulco parieto-occipital (SPO). 
Tabela 2. Frequências e percentagens de identificação da incisura pré-occipital (IPO) e da protuberância óssea (PO) associada nas imagens de tomografia computadorizada.

\begin{tabular}{lcccccr}
\hline \multirow{2}{*}{ Achados } & \multicolumn{2}{c}{ Lado direito } & \multicolumn{2}{c}{ Lado esquerdo } & \multicolumn{2}{c}{ Ambos os lados } \\
& Frequência & $\%$ & Freqüência & $\%$ & Freqüência & $\%$ \\
\hline IPO & 18 & 17,5 & 25 & 24,3 & 43 & 20,9 \\
PO & 19 & 18,4 & 26 & 25,3 & 45 & 21,8 \\
IPO e PO & 11 & 10,7 & 13 & 12,6 & 24 & 11,6 \\
Indeterminado & 55 & 53,4 & 39 & 37,8 & 84 & 45,7 \\
Total & 103 & 100 & 103 & 100 & 206 & 100 \\
\hline
\end{tabular}

Tabela 3. Frequências e percentagens de identificação da incisura pré-occipital (IPO) e da protuberância óssea (PO) associada, nas imagens de ressonância magnética.

\begin{tabular}{lcccccr}
\hline \multirow{2}{*}{ Achados } & \multicolumn{2}{c}{ Lado direito } & \multicolumn{2}{c}{ Lado esquerdo } & \multicolumn{2}{c}{ Ambos os lados } \\
& Frequência & $\%$ & Freqüência & $\%$ & Freqüência & $\%$ \\
\hline IPO & 10,0 & 9,61 & 13,0 & 12,5 & 23,0 & 11,05 \\
PO & 9,0 & 8,65 & 6,0 & 5,76 & 15,0 & 7,21 \\
IPO e PO & 81,0 & 77,7 & 83,0 & 79,82 & 164,0 & 78,86 \\
Indeterminado & 4,0 & 3,84 & 2,0 & 1,92 & 6,0 & 2,88 \\
Total & 104,0 & 100 & 104,0 & 100 & 208,0 & 100 \\
\hline
\end{tabular}

\section{DISCUSSÃO}

O LO apresenta-se sob a forma de pirâmide triangular com ápice posterior (ponta do LO), base anterior, três faces (medial, superolateral e inferior) e três bordas (superomedial, inferolateral e inferomedial). Em macacos e no feto humano, o LO está completamente limitado, em sua extremidade anterolateral, pelo sulco perpendicular externo ou parieto-occipital externo'. Não ocorre o mesmo no homem adulto, em que este sulco se encontra oculto ou interrompido por pregas anastomóticas, que unem giros vizinhos. Em consequência da falta de limite anterolateral, os giros do LO apresentam-se em extensão contínua com os giros dos lobos parietal e temporal. Assim, o limite anterolateral do LO é representado de maneira arbitrária pela linha imaginária ao longo do trajeto do sulco desaparecido. Esta linha, paralela ao sulco parieto-occipital, une a terminação desse sulco, na borda superomedial do hemisfério, à incisura pré-occipital, na borda inferolateral do hemisfério.

Sobre a grande circunferência da tenda do cerebelo, na parede superior do seio transverso, aproximadamente $20 \mathrm{~mm}$ posterior ao ponto lateral da bor- da superior da pirâmide petrosa (ângulo sinodural), encontra-se uma prega (dobra, ruga) da dura-máter. Ela forma uma ponte pregueada sobre a dura-máter da parede superior do seio transverso. Tal estrutura não é descrita nos textos clássicos de anatomia ${ }^{1,2}$, nem listada no Nomina Anatomica ${ }^{3}$. Também não foi encontrada em pesquisa bibliográfica no Index Medicus (para referências anteriores a 1966) e na Medline (para referências após 1966), quando foram cruzados os termos dura-mater, tentorium cerebelli e plica. Ela não é referida nos estudos clássicos de Klintworth ${ }^{4,5}$ e Bull ${ }^{6}$ sobre anatomia, filogenia e ontogenia da tenda do cerebelo.

Na face interna do crânio essa prega dural corresponde, geralmente, a pequena elevação ou protuberância óssea próxima do ponto onde a sutura lambdóide cruza a borda superior do sulco do seio transverso, antes de alcançar o astério. Essa protuberância e a prega do tentório, colada a ela, estão em relação direta com a incisura pré-occipital, sendo, aparentemente, a causa dessa impressão na borda inferolateral do hemisfério cerebral.

A prega dural da tenda do cerebelo é acidente anatômico constante, aparentemente responsável 
pela incisura pré-occipital. Merece, portanto, denominação precisa. Sugerimos "plica tentorial préoccipital". O termo latino plica é usado em anatomia como significando prega ou dobra. A denominação proposta tem a vantagem de indicar a localização da prega dural (tentório) e de sugerir sua relação com a incisura pré-occipital e o limite anterior do LO (pré-occipital).

A protuberância óssea próxima ao ponto onde a sutura lambdóide cruza o bordo superior do sulco do seio transverso, juntamente com a plica tentorial pré-occipital colada a ela, praticamente coincide com o astério, estando poucos milímetros acima dele (Fig 4). Assim, este ponto craniométrico constitui a referência externa para a posição da incisura pré-occipital e, portanto, do limite inferolateral do LO. A protuberância óssea e a incisura pré-occipital associadas à plica tentorial pré-occipital são identificadas em $54,3 \%$ das TC e em $97,12 \%$ das RM.

A extremidade superior do sulco parieto-occipital encontra-se logo à frente do lambda, distando deste $11,5 \mathrm{~mm}( \pm 4,4)$ (Tabela 1$)$; ambas as estruturas são facilmente identificadas na RM, distando entre si, em média, 9,67 mm. Assim, os valores obtidos nas peças anatômicas e nos exames de imagem são bastante próximos. Broca ${ }^{7}$, em medições em cadáveres, encontrou o valor de $10 \mathrm{~mm}$ para a distância entre o lambda e a extremidade superior do sulco parieto-occipital. Este valor é bastante próximo ao encontrado no presente material $(11,5 \mathrm{~mm})$.
Com a finalidade de localização cirúrgica (topografia cranioencefálica), o limite anterior do LO pode ser representado sobre o crânio. Consiste na linha que liga o ponto localizado 10 a $11 \mathrm{~mm}$, aproximadamente, à frente de lâmbda (correspondente ao sulco parieto-occipital), ao astério (correspondente à incisura pré-occipital) (Fig 4). Estes pontos craniométricos são facilmente identificados sobre o crânio. O lambda dista, aproximadamente, $70 \mathrm{~mm}$ acima do ínio, enquanto o astério pode ser palpado cerca de $50 \mathrm{~mm}$ acima da ponta do processo mastóideo'.

A protuberância óssea e a incisura pré-occipital, em sua relação com a plica tentorial pré-occipital e a correspondência entre o lambda e a extremidade superior do sulco parieto-occipital parecem referências confiáveis para definir o limite anterolateral do LO, podendo ser aplicadas aos exames de imagem, especialmente à ressonância magnética, e à delimitação de acesso cirúrgico (topografia cranioencefálica).

\section{REFERÊNCIAS}

1. Testut L. Traité d'anatomie humaine. Vol3. Paris: Gaston Doin Editeurs, 1930: 6-15.

2. Gray H. Anatomy descriptive and surgical. London: John W. Parker and Son, 1858: 447-449.

3. Federative Committee on Anatomical Terminology. Terminologia anatomica. Stuttgart:Thieme, 1998.

4. Klintworth GK. The ontogeny and growth of the human tentorium cerebelli. Anat Rec 1967;158:433-442.

5. Klintworth GK. The comparativa anatomy and phylogeny of the tentorium cerebelli. Anat Rec 1968;160:635-642.

6. Bull JW. Tentorium cerebelli. Proc R Soc Méd 1969;62:1301-1310.

7. Broca P. Sur la topographie cranio-cérébrale ou sur les rapportes anatomiques du crane et du cerveau. Rev d'Anthrop 1876;5:193-248. 